\title{
AÇÃO JUDICIAL EM POLÍTICAS PÚBLICAS NO BRASIL
}

\author{
${ }^{1}$ Carmen Sílvia Righetti Nóbile \\ ${ }^{2}$ Neide Aparecida de Souza Lehfeld
}

\section{RESUMO}

Partimos do pressuposto de que os direitos fundamentais são considerados o núcleo essencial das Constituições e do Estado Democrático de Direito, e para a sua concretização é necessário uma ação concreta do Estado na execução das Políticas Públicas. Tal quadro pode ensejar a busca de resposta em outra esfera: a intervenção judicial. Trata-se de uma pesquisa teórica, por meio do debate sobre a seguinte questão: Depois de esgotadas as tentativas em outras instâncias (de natureza política e administrativa), pode-se buscar a intervenção do Poder Judiciário, visando à implantação de políticas públicas pertinentes aos direitos fundamentais sociais?

Palavras-chave: Poder judiciário, Políticas públicas, Direitos fundamentais, Estado democrático de direito

\section{ACCIÓN JUDICIAL EN POLÍTICAS PÚBLICAS EN BRASIL}

\section{RESUMEN}

Asumimos que los derechos fundamentales se consideran el núcleo esencial de la constitución y el imperio de la democracia, y para lograrlos Estado acciones concretas en la ejecución de políticas públicas.Esta situación puede dar lugar a la búsqueda de respuestas en otra esfera: la intervención judicial. Esta es una investigación teórica, a través del debate sobre el asunto: Después de haber agotado todos los intentos en otros foros (político y administrativo), se puede solicitar la intervención del poder judicial, con miras a la aplicación de las políticas pertinentes los derechos sociales fundamentales?

Palabras-claves: Poder judicial, Políticas públicas, Los derechos fundamentales, Estado democrático

\footnotetext{
1 Doutora em Serviço Social pela Universidade Estadual Paulista Júlio de Mesquita Filho - UNESP, São Paulo. (Brasil). Assistente social do Tribunal de Justiça do Estado de São Paulo, São Paulo. (Brasil). E-mail: crighetti@tjsp.jus.br

2 Doutora em Serviço Social pela Pontifícia Universidade Católica de São Paulo - PUC/SP, São Paulo. (Brasil). Professor de estágio da Associação de Ensino de Ribeirão Preto, São Paulo. (Brasil). E-mail: nlehfeld@unaerp.br
} 


\section{INTRODUÇÃO}

Na América Latina e, em igual sentido, no Brasil, não obstante a consignação de amplas garantias em suas Constituições, especialmente no que tange aos direitos fundamentais sociais, aponta-se como problema comum dos Estados, a ausência de efetivação concreta de direitos humanos. Os direitos fundamentais são considerados o núcleo essencial das constituições e do Estado Democrático de Direito. Todavia, especificamente os direitos fundamentais sociais, demandam uma atuação estatal para sua efetivação.

São esses direitos que dependem, para sua eficácia, de uma ação concreta do Estado e da atuação do Poder Executivo na execução das políticas públicas que garantam os direitos conquistados: trava-se o embate entre a efetividade das normas constitucionais frente as limitações impostas pelo orçamento.

Mesmo diante de uma profunda mobilização social na busca da concretização dos direitos fundamentais por intermédio das políticas públicas, os Poderes Públicos podem permanecer inertes.

Tal quadro pode ensejar a busca de resposta em outra esfera, através da intervenção judicial. Uma discussão mais recente, visando a concretização de direitos tem tomado a pauta dos Tribunais, em face da falta de implantação e/ou implementação de políticas públicas por parte do Estado, sendo os meios necessários para a efetivação dos direitos fundamentais e concretização de direitos.

O presente artigo trata-se de uma pesquisa teórica, apresentando as várias abordagens sobre o assunto, por meio do debate sobre as seguintes questões: O Poder Judiciário pode ou não intervir nas políticas públicas para aferir sua compatibilização com os objetivos fundamentais das leis? Até que ponto a intervenção do Poder Judiciário com vistas ao cumprimento das políticas públicas na implementação de direitos sociais caracteriza afronta à divisão e à independência dos poderes que constituem o Estado Democrático de Direito? Depois de esgotadas as tentativas em outras instâncias (de natureza política e administrativa), pode-se buscar a intervenção do Poder Judiciário, visando à implantação de políticas públicas pertinentes aos direitos fundamentais sociais?

Algumas referências foram utilizadas: Appio (2012); Canela Junior ( 2011); Giovanni (2009); Grinover (2013); Bucci ( 2013); Watanabe (2013); Zufelato (2013).

Nesse artigo serão apresentadas as várias abordagens acerca do assunto: a dos que sustentam a tese de que todos os direitos fundamentais sociais são tuteláveis pelo Judiciário; a dos que defendem a possibilidade da intervenção parcial e a dos que afirmam ser impossível qualquer interferência do judiciário nas políticas públicas. 
Será objeto de exame, além disso, os entraves à mencionada intervenção, como a alegação de que o Poder Judiciário não pode extrapolar, por meio de suas decisões, o âmbito da esfera do administrador público, sob pena de infringir o princípio da separação dos poderes. Outro argumento utilizado é do impacto econômico-financeiro, que recorre à ideia de que a efetividade dos direitos sociais estaria condicionada às capacidades financeiras do Estado, ou seja, ao "princípio da reserva do possível”.

\section{POLITICA PÚBLICA NO BRASIL E OS DESAFIOS DO CONTROLE SOCIAL}

O Estado brasileiro, ao se integrar com o sistema normativo internacional de proteção dos direitos humanos, adotou o referencial ético que deu a origem à Declaração dos Direitos Humanos de 1948, optando pela proteção integral e irrestrita dos direitos humanos.

A Constituição estabelece que a atividade para a satisfação dos direitos fundamentais sociais pertence, prioritariamente, por meio de atividades do Poder Legislativo e Poder Executivo (através da implantação/implementação de políticas públicas).

As políticas públicas podem ser examinadas de vários ângulos e cada um dele representa um olhar diferente que capta um determinado aspecto da realidade e, certamente, com algum objetivo especifico.

Segundo Giovanni (2009) não existe uma grande teoria sobre as políticas públicas. Nós é que temos que fazer um recorte e assumir a responsabilidade sobre ele.

Mas, por que um tema ou questão torna-se o assunto de uma política pública? Somos tentados a responder com uma evidência: há uma política pública, porque há um problema para resolver, como se a política pública apresentasse uma "boa prática" ou como se a política pública devesse resolver os problemas dos necessitados. Esta explicação está cheia de senso comum, pois nem toda demanda social se torna política pública, como aponta o Prof. Giovanni:

Tal conceito vai além da ideia de que uma política pública é simplesmente uma intervenção do Estado numa situação social considerada problemática. Mais do que isso, penso a política pública como uma forma contemporânea de exercício do poder nas sociedades democráticas, resultante de uma complexa interação entre Estado e sociedade, entendida aqui num sentido amplo, que inclui as relações sociais travadas também no campo da economia. Penso, também, que é exatamente nessa interação que se definem as situações sociais consideradas problemáticas, bem como as formas, os conteúdos, os meios, os sentidos e as modalidades de intervenção estatal. (GIOVANNI, 2009, P. 1-2) 
Essa conceituação depende da concretização histórica de alguns requisitos que configuram as modernas democracias; pressupõe-se uma capacidade mínima de planificação consolidada nos aparelhos do Estado.

A política publica é mais que uma política, é um modo institucionalizado de agir, elegendo situações problemáticas que o Estado irá intervir, não nascem prontas, são construídas.

Atualmente, o Poder Executivo tem se auxiliado (ou apropriado) das atividades dos chamados Conselhos de Gestão no que diz respeito à elaboração das políticas públicas no Brasil, sobretudo nas áreas da saúde, criança e adolescente, educação, assistência social, segurança entre outros. Tais conselhos, contam com a participação de diversos segmentos da sociedade, compostos por representantes estatais, da sociedade civil e de prestadores de serviços públicos (Poder Público, entidades de classe, associações, clubes de serviços, etc); composição essa, que torna o processo decisório mais permeável aos diversos interesses implicados na elaboração e execução de politicas públicas, favorecendo decisões mais justas e legítimas e contribuem para o diagnóstico das prioridades nas áreas correspondentes aos direitos sociais, formulando projetos, encaminhando sugestões e requerimentos no sentido de que sejam implantados/implementados pelo Poder Executivo.

Pode-se afirmar que no Brasil, os conselhos ${ }^{1}$ são resultantes do esforço de mobilização social e dos debates públicos que precederam a Constituição Federal de 1988; buscando possibilitar que a sociedade compartilhe, com o Estado, a definição de prioridades e a formulação de políticas públicas como forma de exercício da cidadania e de controle social. A novidade estabelecida nessa concepção é o controle do Estado realizado por toda a sociedade.

Apesar de o controle social ser um principio conquistado contido na Constituição de 1988, somente na década de 1990 que foram implementados, a partir das diferentes leis complementares, tais como exemplo: o SUS (1990), o ECA (1990), LOAS (1993) entre outros. Tais leis instituem o controle social em duas instâncias formais, que são também espaços de luta: as conferências e os conselhos.

As conferências são eventos que devem ser realizados periodicamente para discutir a politica em cena, em cada esfera de governo, e propor diretrizes de ação. As deliberações das conferências são norteadoras para a implantação e implementação de políticas públicas.

1 A função dos conselhos é garantir, portanto, os princípios da participação da sociedade nos processos de decisão, definição e operacionalização das politicas públicas. São instrumentos criados para atender e cumprir o dispositivo constitucional no que tange ao controle social dos atos e decisões governamentais. 
Já os conselhos são espaços de caráter permanente, deliberativo e paritário. Compõese por $50 \%$ de membros da sociedade civil e outros $50 \%$ representantes do governo, com o principal objetivo de discutir, elaborar e fiscalizar a política em tela, em cada esfera de governo. (SOUZA, 2010).

Essa estrutura, pode representar uma avanço importante na ampliação dos canais de participação política, bem como na renovação das formas de representação e de negociação dos interesses. Contudo, a observação de experiências tem evidenciado que a efetivação de suas potencialidades tem enfrentado dificuldades. "O processo de descentralização/municipalização não se contrói por decretos e leis, o que requer por parte da sociedade civil e do próprio Estado, a predisposição a romper com hábitos e práticas políticas que resultam na centralização". (COELHO, 1999, p. 93).

Mesmo que não tenham poder efetivo para decidir sobre a política pública, os conselhos têm poder de veto sobre as decisões do governo, podendo paralisar obras, vetar convênios, suspender o repasse de recursos, etc... Os avanços ou recuos são mediados pela correção de forças num dado momento, diante das disputas travadas no interior dos conselhos, do locus de disputa de propostas e projetos, do embate politico, do confronto, além da negociação, articulação e construção de alianças.

Embora não sejam os únicos e possíveis canais de participação da sociedade, os Conselhos revestem-se de caraterísticas particulares, postos que são canais permanentes e sistemáticos com garantia jurídico/formal.

No Brasil, a Constituição Federal de 1988, Eca e outras leis, trouxeram a esperança de que, enfim, as promessas marcadamente voltadas para a implementação do necessário para a dignidade humana seriam alcançadas, se transformando em algo real e extensível a todos. No entanto, depois da promulgação da CF, a referida esperança mostra-se arranhada em decorrência da não concretização de vários direitos sociais.

Os direitos fundamentais são considerados o núcleo essencial das constituições e do Estado Democrático de Direito. Todavia, especificamente os direitos fundamentais sociais, demandam uma atuação estatal para sua efetivação.

Há, no campo dos direitos sociais, um maior grau de defasagem entre a norma jurídica e a sua efetiva aplicação. Trata-se de uma defasagem comum a todas as áreas, mas que, na social, parece ser maior, basicamente porque os direitos sociais dependem muito, para serem efetivamente usufruídos, de decisões políticas cotidianas, tomadas no dia-a-dia, em função de mil e uma contingências políticas, econômicas ou financeiras. Os direitos sociais trazem consigo, como sabemos, a 'necessidade de alocações expressivas de recursos: financeiros, humanos, técnico-cientificos, organizacionias, políticos, seja para que se financiem os direitos, seja para viabilizá-los no plano organizacional (NOGUEIRA, 2005, p.10). 
São esses direitos que dependem, para sua eficácia, de uma ação concreta do Estado e da atuação do Poder Executivo na execução das políticas públicas que garantam os direitos conquistados: trava-se o embate entre a efetividade das normas constitucionais frente as limitações impostas pelo orçamento.

Mesmo diante de uma profunda mobilização social na busca da concretização dos direitos fundamentais por intermédio das políticas públicas, os Poderes Públicos podem permanecer inertes. Tal quadro pode ensejar a busca de resposta em outra esfera, através da intervenção judicial.

O tema é muito polemico, principalmente pelo fato que essa quebra de paradigma (possibilidade do juiz na determinação judicial visando cumprir as Politicas Publicas, seja confundido como "administrador público" na materialização de políticas públicas) encontra óbices não somente jurídico, como o principio da separação e harmonia dos poderes e o principio da legalidade; mas, sobretudo fáticos, como é o caso da escassez de recursos financeiros do Estado, ou, como a Doutrina e os Tribunais tem preferido denominar, o princípio da reserva do possível.

Ao que se sabe, a construção teórica do princípio da reserva do possível tem origem na Alemanha na década de 70 , com o constitucionalista alemão Peter Häberle. O conceito trabalha com o fato de que a efetividade dos direitos sociais estaria sob a reserva das capacidades financeiras do Estado, especialmente quando se tratarem de direitos fundamentais dependentes de atuação do Poder Executivo. A partir desta concepção, a concretização dos direitos sociais estaria relacionada à disponibilidade de recursos financeiros por parte do Estado, disponibilidade esta que estaria localizada no campo da discricionariedade das decisões governamentais e parlamentares, sintetizadas no orçamento público. O caso que saltou aos olhos dos doutrinadores na Alemanha foi a disputa versando sobre o direito de acesso ao ensino superior e as restrições fáticas existentes (GARCIA, 2008).

Essa questão levou a doutrina a muitos debates, mas especialmente, deu surgimento a teorias que pretendem determinar quais limites ou restrições pode o judiciário intervir nas políticas públicas e contrabalançar as fontes de recursos e arrecadação do Estado com os a necessidade de investimentos sociais. É possível? Esta será a discussão travada (formulada) no nosso próximo item.

\section{INTERVENÇ̃̃o JUDICIAL EM POLÍTICAS PÚBLICAS NO BRASIL}

A consagração de uma ampla gama de direitos e a democratização ao acesso à justiça, decorridos da constituição de 1988 estimularam a procura por soluções judiciais quando os 
direitos sociais não são concretizados com ações do poder público. Os que buscam os Tribunais, como meio de garantir direitos, deposita no Judiciário a confiança que perdeu em outros Poderes.

Não há registro unificado sobre o total de ações desse tipo ajuizadas em todo o País, mas vale transcrever o que tem sido divulgado. Segundo informações publicadas na impressa, em setembro de 2009, só no Estado de São Paulo tramitavam 25 mil ações, obrigando a Secretaria Estadual de Saúde a gastar R \$ 25 milhões por mês para cumprir ordens judiciais de distribuição de medicamentos. No Rio Grande do Sul, apenas no primeiro semestre de 2008 teriam sido impetradas 4,5 mil novas ações, forçando um gasto de $\mathrm{R} \$$ 6,5 milhões mensais. Segundo o Ministério da Saúde, a União gastou em 2009 R\$ 83,16 milhões com a compra de medicamentos determinada por 1.780 ações judiciais. Esse valor seria $75 \%$ superior ao gasto em 2008. (SADEK, 2013).

Autoridades municipais, estaduais e federais, por sua vez, sustentam o argumento segundo o qual as decisões da magistratura têm desorganizado o planejamento e as finanças dos Municípios, dos Estados e da União. Afirmam que a interferência judicial tem obrigado administradores públicos a redefinirem prioridades e a se defrontar com uma situação de alteração na alocação de recursos. Alegam ainda que, os recursos que têm sido desviados para o cumprimento de decisões judiciais, seria possível construir novos hospitais e unidades de pronto atendimento, beneficiando desta forma um maior número de pessoas. (SADEK, 2013, p. 23).

Outra situação recorrente é em relação às demandas que visam à obtenção de determinado medicamento à custa do Estado ou a realização de exames ou procedimento cirúrgico não disponibilizado pelo SUS, tal demanda têm sido utilizadas com frequência na prática forense, através de ações estritamente individuais.

Grinover (2013) aponta críticas às essas decisões de demandas individuais, que concedem ao autor tratamentos caríssimos no exterior, ou a aquisição de remédios experimentais que sequer foram liberados no Brasil. A saúde é uma política pública que deve propiciar o atendimento do maior número de pessoas com o mesmo volume de recursos.

O mesmo posicionamento apresenta Jacob:

O Poder Público, como visto, ao garantir o direito constitucional à vida e à saúde (mínimo existencial), atentou-se para a limitação dos seus recursos materiais (reserva do possível), a fim de atender um maior número de pessoas com os recursos disponíveis, em perfeita observância aos princípios da razoabilidade e da eficiência, que devem nortear os atos administrativos. Dessa forma, a função precípua do ente público é racionalizar os seus recursos financeiros, de modo a garantir o acesso de todos às ações e serviços de saúde, não me parecendo justo e nem adequado que os parcos recursos destinados ao Munícipio pelo SUS sejam utilizados com uma 
minoria que busca, através do Poder Judiciário, utilizar-se de medicamentos onerosos que não estão incluídos dentre aqueles de fornecimento obrigatório. (JACOB, 2013, p. 276).

Ressaltando ainda, que quando determinado medicamento é disponibilizado, foi avaliado pelos técnicos da ANVISA (Agência Nacional de Vigilância Sanitária), que se baseia na FDA - agencia americana de drogas e alimentos (órgão americano equivalente a ANVISA). Essas ações tem gerado um embaraço jurídico: a advogacia Geral da União e as Secretarias da Fazenda dizem que os governos não devem fornecer um remédio, sem registro na ANVISA e sobre o qual faltam evidências sobre a eficácia e a segurança.

Para Appio (2012) ao promover uma ação individual, o cidadão não pretende a universalização do serviço, mas apenas garantir sua vaga. As ações individuais não teriam condições de propiciar o planejamento de políticas públicas, pois se estaria julgando uma situação deslocada da perspectiva global do fenômeno: são ações individuais visando à implementação de "políticas públicas".

De grande valia, pois, a advertência de José Reinaldo de Lima Lopes, no sentido de que todo o cuidado deve ser reservados em relação ao provimento jurisdicional que conceda direitos fundamentais sociais, a fim de que o Poder Judiciário não assuma a "fila de atendimento" dos órgãos da administração. É preciso, segundo o autor, que o provimento jurisdicional permita o atendimento igualitário de todos os cidadãos. (CANELA JÚNIOR, 2011, p. 105).

Resultando que uma necessidade individual demanda e pressupõe a prévia implementação de uma determinada política social. Sendo que há um conflito entre a perspectiva da lei e da política pública. A lei lida com a conduta dos outros, tem um olhar retrospectivo: “o que ocorreu”, retrospectivamente olha se alguém errou. Já a visão de Politica Pública é um olhar prospectivo, busca aprender com aquele conflito para pensar o futuro. A ação em Politica Pública é ação em escala, buscando o atendimento da coletividade, do grupo de pessoas e não do individuo. Quando um gestor pensa a questão de escala, representado através de indicadores, quer produzir ação, movimento, mudar o cenário. Busca-se recursos para produzir resultados, considera-se o universo: o todo. Não se trata se retrospectivamente alguém errou, mas o que alcançou - busca a efetividade. Isso é difícil no processo judicial, pois no direito há conflito entre o individual e o coletivo (BUCCI, 2013).

Grinover (2013) alerta que, embora as ações estritamente individuais possam ter efeito positivo, influindo sobre a ampliação da política pública, deve-se tomar maior cuidado e observância do pressuposto e dos limites em relação às essas ações, cujo acolhimento diminuirá a verba destinada à política pública geral. 
Para Gonçalves não basta a efetivação dos direitos sociais de forma individual: " $a$ concretização do direito social apenas para alguns não é direito, é privilégio" (GONÇALVES, 2013, p. 18).

Appio (2012) entende ser descabida uma demanda individual pleiteando a garantia de um direito fundamental quando a politica pública correspondente não esteja implementada, sob pena de afronta ao principio da separação dos poderes e à isonomia. Essa demanda não pode ser atendida pelo juiz no caso concreto, através de uma ação individual, pois se busca a proteção de um direito coletivo através de uma demanda de natureza individual.

Mas, Canela Júnior (2011) aponta que não há como se determinar na relação jurídica, quais seriam exatamente todos os beneficiários, pois os direitos fundamentais sociais atingem um numero indeterminado de pessoas, porquanto o seu âmbito pretendido de abrangência é o conjunto de toda a sociedade. Nessa mesma linha de pensamento segue Zufelato (2013):

Existem algumas demandas, chamadas de pseudoindividuais, que, embora sejam propostas como ações individuais, possuem objeto que transcende a exclusividade da esfera jurídica do autor, de forma que a decisão sobre ela inexoravelmente atingirá uma coletividade de sujeitos; essa demanda, em realidade, é individual quanto ao autor, mas coletiva quanto aos efeitos. Seria o caso, por exemplo, de deficiente físico que pleiteia em seu nome a adaptação dos meios de transporte público para o beneficiar. Uma vez julgada procedente tal demanda, adquirirá efeitos coletivos, alcançando a todos os deficientes físicos que utilizem esses mesmos meios de transporte. (ZUFELATO, 2013, p. 328)

Se o Poder Judiciário confere um direito social a uma pessoa ou a um grupo determinado de pessoas, por certo, todos que estejam na mesma situação são merecedoras do direito. O principio de isonomia impõe um tratamento idêntico, por parte do Estado, em favor de todos os cidadãos que se encontrem em uma mesma situação de necessidade. Existem, portanto, demandas individuais com efeitos coletivos, que servem aos interesses ou direitos difusos e coletivos. Da mesma forma pontua Watanabe (2013):

Mas é certo também que, por intermédio de uma demanda individual, podem ser protegidos direitos e interesses coletivos....outro exemplo: inconformado com a fixação das mensalidades de uma escola, um pai de aluno pede a correção da tabela de custos, para adaptá-la aos critérios legais...a demanda individual terá efeitos coletivos, beneficiando, ou não, todos os estudantes da escola. [...] São “ individuais" apenas no sentido de que são propostas por indivíduos, mas a pretensão é de alcance coletivo, pois beneficia a totalidade das pessoas que se encontram na mesma situação, e não somente o autor da ação. (WATANABE, 2013, p. 145- 146)

Como se observa o Poder Judiciário constituiu-se um ator com capacidade de provocar impactos significativos no embate político, na elaboração e execução de políticas públicas, em 
áreas que tradicionalmente são de competências dos poderes Legislativo e Executivo.

No Brasil, durante muito tempo os tribunais assumiram a posição de não poder adentrar no mérito da administração pública. Mas para a jurista Ada Pellegrini Grinover, a Constituição de 1988 trouxe a verdadeira guinada em termos de ação popular, através do art. 5, inciso LXXIII, que introduziu a seguinte redação:

Art. 5, inciso LXXIII: "Qualquer cidadão é parte legítima para propor ação popular que vise a anular ato lesivo ao patrimônio público ou de entidade de que o Estado participe, à moralidade administrativa, ao meio ambiente e ao patrimônio histórico e cultural, ficando o autor salvo comprovada má-fé, isento de custas judiciais e do ônus da sucumbência" . (GRINOVER, 2013, p. 127)

Ora, se o Estado não promoveu a satisfação dos direitos fundamentais, nasce a pretensão de utilizar-se de ação Judicial para obter a reparação da lesão causada, do que resulta a intervenção direta dos juízes em áreas que até então, eram exclusivas dos demais poderes.

Os direitos fundamentais são prioritários, porque os bens da vida por eles protegidos são essenciais à existência humana. Eles devem ser atendidos com absoluta preferência, pois envolvem a discussão acerca da dignidade do ser humano e constitui o pilar do sistema ético de referência de todo o sistema normativo. (CANELA JÚNIOR, 2011).

A mera previsão abstrata do direito fundamental, ou seja, apenas a lei sem a sua concessão material, implica igualmente lesão e, portanto, sujeita o Estado à obrigação de satisfazê-lo. Assim para Canela Júnior (2011) todas as lesões a direitos fundamentais sociais levadas ao conhecimento do Poder Judiciário deverão ser obrigatoriamente apreciadas, pois trata-se, de limitações à sua efetivação.

Todas as lesões a direitos fundamentais sociais levadas ao conhecimento do Poder Judiciário deverão ser obrigatoriamente apreciadas, desde que, é claro, sejam respeitados os mecanismos técnicos inerentes ao processo. A lide, pois, será definitivamente dirimida pelo Poder judiciário (CANELA JÚNIOR, 2011, p. 94).

Para Watanabe, os demais direitos fundamentais sociais, que não correspondam ao núcleo básico da dignidade humana e por isso não são asseguradores do "mínimo existencial", e tampouco estejam consagrados em normas constitucionais, não deveriam ser apreciados pelo Judiciário sem a prévia ponderação do Legislativo ou do Executivo, por meio de definição de política pública especifica. Em relação a eles deve ser resguardado o debate democrático e preservado o pluralismo politico, e o respeito aos devidos Conselhos de Direitos. (WATANABE, 2013).

Para a jurista Ada Pellegrini Grinover (2013) o Poder Judiciário pode exercer a intervenção nas políticas públicas para aferir sua compatibilização com os objetivos 
fundamentais da República Federativa do Brasil.

De acordo com o disposto no art. 5 XXXV, da Constituição Federal "a lei não excluirá da apreciação do Poder Judiciário lesão ou ameaça de direito". Assim, nenhuma afirmativa de lesão ou ameaça a direito poderá ser excluída da apreciação do Poder Judiciário. (GRINOVER, 2013, p. 143)

O mesmo posicionamento tem Maria Paula Dallari Bucci "não é se pode ou não haver controle judicial, (isso é certo, em virtude da CF, art $5 \mathrm{XXXV}$ ), mas qual o seu conteúdo e quais os limites da decisão judicial”( BUCCI, 2013, p.192).

Mas Appio (2012) pontua ainda que o Poder Judiciário não pode intervir nas Políticas Públicas, pois tem a função de fiscalizar os demais poderes.

Portanto, o Poder Judiciário, como responsável pela fiscalização dos demais Poderes exercentes das funções de governo, não pode substituir esta atividade, a titulo de fiscalizar sua escorreita execução, sob pena de autorizar a intervenção dos Poderes Legislativo e Executivo na atividade judicial. ( APPIO, 2012 , p.151-152).

Como se observa a doutrina não é pacifica a respeito: há os que defendem a tese de que todos os direitos fundamentais sociais são tuteláveis pelo Judiciário sem necessidade de indagar se existem, ou não, os recursos necessários para a sua implementação, como os que defendem a possibilidade parcial da intervenção e os que defendem a impossibilidade de qualquer intervenção.

Canela Júnior (2011) pontua que a lesão a direito fundamental social pode operar-se basicamente de duas maneiras. A primeira consiste na omissão completa do Estado na satisfação espontânea dos direitos constitucionais subjetivos previstos no art. 6 da Constituição Federal. A segunda forma de lesão a direitos fundamentais sociais decorre do comportamento, comissivo (ação que a norma proíbe) ou omissivo (omissão de quem tinha o dever de agir) do Estado. Sendo esse também o posicionamento de Gonçalves:

O Poder Judiciário pode atuar no campo das políticas públicas diante de duas situações distintas: a primeira delas relativa à hipótese na qual se verifica a ausência completa da política; a segunda, quando se constata que determinada política mostra-se insuficiente. (GONÇALVES, 2013, p. 280).

Quando ocorre uma omissão parcial da política pública posto que ela é insuficiente para atender determinada demanda, ou o critério adotado pela politica pública exclui certos grupos ou cidadãos de sua abrangência, o Judiciário pode intervir nas políticas públicas, quer para implementá-las, quer para corrigi-las quando equivocadas. (GRINOVER, 2013).

Mas Appio aponta: 
A atividade de revisão judicial deve estar assentada nos seguintes pressupostos: 1) a política social já se encontra abstratamente prevista na lei ou na Constituição e corresponde à outorga de direitos coletivos, 2) o Poder Executivo ainda não implementou a política social prevista na Constituição, 3) O Poder Executivo, ao implementar a política social, rompeu com o principio de isonomia ( atendimento parcial de um dever constitucional). $\mathrm{O}$ autor coletivo deverá, ainda, preencher os seguintes requisitos específicos: 1) deverá indicar a fonte de financiamento da implantação ou extensão de um programa social; e 2) terá de respeitar a lei orçamentária anual ( principio da reserva da atividade legislativa). (APPIO, 2012, p.168).

O autor acima argumenta que é o autor da ação que deve indicar a fonte de financiamento da implantação ou extensão da política pública, de outra forma, Jorge Neto não tem o mesmo entendimento:

É o réu quem deverá demonstrar a medidas de suas possibilidades para a implementação de uma determinada política pública ou, até mesmo, sua absoluta impossibilidade material para tanto. $\mathrm{O}$ autor não tem condições de fazê-lo, até porque não conhece a fundo as limitações materiais, estruturais ou de qualquer outra ordem a que está sujeito o Poder Público. Assim, ao apresentar defesa, a pessoa jurídica de direito público poderá alegar a inexistência da alegada ofensa aos direitos fundamentais e/ou a impossibilidade de alcançar os objetivos pretendidos com a inicial. $\mathrm{Na}$ instrução processual, abrir-se-á então, uma ampla discussão acerca desses elementos. (JORGE NETO, 2008, p. 150)

A pessoa que está em busca de uma resposta a um direito não concretizado pelo poder público, muitas vezes, não tem acesso e/ou conhecimento das limitações orçamentárias, ou das fases de implantação da Política Pública. Essas limitações não afastariam o reconhecimento da violação dos direitos fundamentais e a atuação do Poder Judiciário.

Num país como o Brasil, com enormes dívidas sociais, com problema de pobreza, de marginalização, de desigualdades sociais e regionais, de falta de moradia, de distribuição desigual de rendas e outros mais, pretender que todos os direitos fundamentais sociais sejam implementados de uma só vez, inclusive com a intervenção do Judiciário, é um sonho idealista que esbarra em obstáculos práticos. O alcance desses objetivos, entretanto, não se dará do dia para a noite. Far-se-á necessário estabelecer prioridades, as quais não são tarefas atingíveis em um curto espaço de tempo. Muito ao contrário, serão alcançados passo a passo, fazendo-se construir paulatinamente e sem desrespeito aos outros princípios fundamentais previstos na Constituição Federal (WATANABE, 2013).

[...] Ilustrativas desse dilema são as ações que postulam direito a vagas em creches, matéria apreciada pelo Supremo Tribunal Federal, que deferiu a postulação dos autores em favor do atendimento ao pleito pela criação de creches pela municipalidade. $\mathrm{O}$ argumento da decisão judicial repousa sobre o caráter obrigatório da disposição constitucional. Mas, em que pese seu 
caráter mandatório, a decisão concreta, naquilo que tange ao interesse das crianças e de seus pais, é remetida novamente à primeira instância [...] E os incidentes da execução, a despeito dos mecanismos processuais coercitivos até mesmo a sanção penal por descumprimento de determinação judicial-, estarão condicionados à elaboração do projeto de lei orçamentária pelo Poder Executivo, aprovação da lei orçamentária pelo Legislativo, devolução da matéria ao Executivo para a execução do orçamento, empenho de recursos, abertura de licitação, realização do processo licitatório, superação da fase de possível contestação judicial do processo licitatório por interessados potenciais ou atuais, início da obra e assim por diante. Há um longo percurso intraestatal à creche pelas crianças- veja a luz. ( BUCCI, 2013, p.199)

As políticas públicas necessitam de um tempo (período) para serem concretizadas, no entanto, também deve se considerar o tempo de omissão da administração pública para e implantação do serviço solicitado. Exemplificando, uma pessoa que perdeu a perna em um acidente e solicita uma prótese, sendo que já entrou com vários pedidos administrativos sem respostas, a mera omissão não justifica a negativa ao serviço.

Então é razoável que o magistrado, após analisar as cadeias de ramificação das políticas públicas, a partir dos núcleos constitucionais de irradiação, acomode o provimento jurisdicional, estabelecendo prazo para que se concretize a efetiva disponibilização do serviço. O magistrado, ao mesmo passo em que julga procedente o pedido, fixa termo para a disponibilização do serviço público, consoante a proporcionalidade exigida no caso concreto, constituindo este o provimento jurisdicional que posteriormente vinculará a conduta do Estado. (CANELA JÚNIOR, 2011, P. 158).

Diante da escassez de recursos ou a ausência de respostas do poder público, o Judiciário depara-se com situações dramáticas nos casos concretos que chegam até ele, tendo muitas vezes, que optar pela vida e ou pela morte. Nessas circunstancias acaba interferindo na competência dos demais poderes - seja ele o Executivo e/ou o Legislativo, responsáveis pela concretização dos direitos através das políticas públicas.

\section{A SEPARAÇÃO DOS PODERES E A RESERVA DO POSSÍVEL: LIMITES A INTERVENÇÃO JUDICIAL EM POLÍTICAS PÚBLICAS}

Para Appio (2012) a substituição da pauta de prioridades do Executivo pela do Judiciário retira do legislador os meios indispensáveis para a consecução de suas finalidades, além de tornar o ato numa perigosa concentração de funções. O Juiz não tem condições de indicar as fontes dos recursos, além do mais, invade uma competência privativa do Poder Legislativo, qual seja a de apreciar a lei orçamentária anual. Trata-se de verdadeira atividade legislativa exercida pelos juízes. 
A determinação de retirada de receita de uma determinada rubrica aprovada em lei ou a redestinação de verbas para as obras e serviços sociais que o juiz reputa prioritários, culminaria por concentrar nas mãos do Judiciário as funções legislativa, executiva e judicial, convertendo-o num "superpoder" (APPIO, 2012 , p.155 -156).

Ainda Jacob (2013) destaca a participação dos Tribunais de contas no tocante a fiscalização das contas públicas:

Importa, ainda, lembrar que a Constituição Federal atribuiu aos Tribunais de Contas, na condição de órgãos acessórios do Poder Legislativo, a competência de julgar às contas públicas no tocante à economicidade, à legitimidade e à legalidade, restando pouco espaço para a análise do Poder Judiciário sem que isto configure, aí sim, violação constitucional. (JACOB, 2013, p. 278)

Dentro dessa perspectiva, temos que um dos entraves constantemente lançados no que diz respeito a possibilidade da intervenção judicial das políticas públicas, sobretudo daqueles pertinentes à implementação de direitos sociais, corresponde à alegação de que o Poder Judiciário não pode avançar, por meio de suas decisões, no âmbito da esfera do administrador público, sob a condição de desnaturar o principio da separação dos poderes (APPIO, 2012). Ao dar liminares, a Justiça impõe um alto custo ao sistema e descoordena as ações do Executivo, em tese responsável por gerenciar de maneira eficiente os recursos.

Outra crítica a intervenção do Poder Judiciário nas políticas públicas, implica a substituição de um ato de vontade dos governos eleitos por um ato de vontade de juízes nãoeleitos.

A substituição do legislador/ administrador público pela figura do juiz não se mostraria politicamente legítima na medida em que (1) o administrador público (Executivo) e o legislador foram eleitos, através do sufrágio universal, para estabelecer uma pauta de prioridades na implementação das políticas sociais e econômicas. Ademais, (2) o Judiciário não possui aparato técnico para a identificação das reais prioridades sociais, tendo de contar, nestes caos, com as informações prestadas pela própria administração Pública. Também (3) o fato de que a atividade - fim do Poder Judiciário é a de revisão dos atos praticados pelos demais Poderes e não sua substituição, enquanto que a atividade-fim da Administração é estabelecer uma pauta de prioridades na execução de sua politica social, executando-a consoante critérios políticos, gozando de discricionariedade, existindo verdadeira "reserva especial de administração". A discricionariedade do administrador não pode ser substituída pela do Juiz. (APPIO, 2012 , p.151).

De outra forma, Zufelato (2013) aponta que o "contraditório amplo e facilitador do diálogo entre as partes" conduzirá dados indispensáveis para uma decisão final justa e 
equânime, sendo este o elemento indispensável que dá sustentação e legitimidade à intervenção judicial nas politicas públicas.

Isso significa, por outro lado, um esvaziamento das críticas dirigidas ao Poder Judiciário enquanto órgão cujos membros não são eleitos pelo voto direto, o que lhe tiraria a legitimidade da decisão em sede políticas públicas. A legitimidade dos juízes e do Poder Judiciário não advém das urnas, como dos Poderes Legislativo e Executivo, mas decorre da participação igualitária das partes no processo mediante o contraditório, bem como do conteúdo de direitos fundamentais do qual se revestem as políticas públicas, o que autoriza sua judicialização. (ZUFELATO, 2013, p. 313)

Como se observa uma postura mais ativa do Poder Judiciário pode implicar possíveis zonas de atrito ou de tensão com os Poderes Executivo e Legislativo. Dentro dessa perspectiva o Poder Judiciário pode ou não ser concebido como um mero carimbador de decisões politicas das demais funções estatais, mantendo uma postura meramente contemplativa, ou exercer uma conduta ativa na apreciação do direito fundamental violado pela omissão do Estado.

Outro argumento utilizado para justificar a ausência de efetividade dos direitos fundamentais sociais é o seu impacto econômico-financeiro. Constata-se que o fenômeno econômico tem sido invocado para impedir a concessão de direitos fundamentais sociais pelo Poder Judiciário. Alega-se, em geral, que o Poder Judiciário não pode conceder direitos, cuja satisfação demandará receitas não disponíveis pelo Estado.

A percepção de que a satisfação dos bens da vida protegidos pelos direitos fundamentais sociais causa vinculação econômica no orçamento do Estado suscitou o tema da "reserva do possível", amplamente difundido na doutrina e na jurisprudência, a ponto de ser utilizado como justificativa para eventual inércia do Poder Judiciário na intervenção de políticas públicas. (CANELA JÚNIOR, 2011).

$\mathrm{Na}$ teoria da reserva do possível, o Estado somente está obrigado a oferecer a garantia de direitos fundamentais, no limite das suas possibilidades, especialmente financeira. A justificativa mais usual da administração para a omissão reside no argumento de que inexistem verbas para implementação de políticas públicas, a qual depende de disponibilidade financeira. Por isso, o investimento a ser feito pelo Estado estaria limitado àquilo que foi determinado no seu orçamento, dentro dos estritos limites determinados pela Constituição.

Para Gonçalves (2013) a invocação da teoria da reserva do possível não pode ser aceita na busca de uma justificativa para os tão baixos níveis na amplitude de atendimento e na eficiência (qualidade) dos serviços públicos.

Ada Pellegrini Grinover, relativamente à "reserva do possível” defende que não basta a simples alegação de falta de recursos, esta deverá ser provada, pela própria administração. 
Ainda, segundo o entendimento da jurista, o acolhimento da alegação de falta de recursos não conduziria à rejeição do pedido pleiteado.

Mas não é só: o judiciário, em face da insuficiência de recursos e de falta de previsão orçamentária, devidamente comprovadas, determinará ao Poder Público que faça constar da próxima proposta orçamentária a verba necessária à implementação da política pública [...]. Desse modo, frequentemente a "reserva do possível" pode levar o Judiciário à condenação da Administração a duas obrigações de fazer a inclusão no orçamento da verba necessária ao adimplemento da obrigação, e a obrigação de aplicar a verba para o adimplemento da obrigação.[...].Nos casos de urgência e violação ao mínimo existencial, o principio da reserva do possível não deverá constituir obstáculo para a imediata satisfação do direito. (GRINOVER, 2013, p. 138 - 139).

O mesmo entendimento tem Canela Júnior (2011), pois considera que ao ser constatada eventual incapacidade financeira (atual) para a satisfação da decisão judicial, a solução não seria o julgamento da improcedência do pedido ou mesmo a extinção do processo por ausência de condições da ação. Comprovada a lesão ao direito fundamental social, a decisão judicial determinaria que os poderes Executivo e Legislativo ajustem as finanças públicas, programando o custeio para a implementação das políticas públicas.

As circunstancias fáticas demonstram que a efetivação de tal direito social seria irrealizável em curto período de tempo, porquanto absorveria o orçamento do município, inviabilizando completamente a prestação de quaisquer serviços públicos.[...] Entretanto, o provimento jurisdicional há de ser ajustado no tempo, e segundo critérios programáticos, a fim de que o orçamento do município seja com ele compatibilizado. (CANELA JÚNIOR, 2011, p.150).

Assim, admite que aqueles direitos fundamentais violados pelo Estado sejam finalmente inseridos na sua agenda programática. E caso o administrador descumpra a ordem ou a decisão Judicial, abrem-se diversas vias para a aplicação de sanções: a) aplicação de multa diária; b) a responsabilização por ato de improbidade administrativa ${ }^{2}$, c) a intervenção no Estado ou no município; d) a responsabilização criminal (GRINOVER, 2013)

Multa diária: medidas de coerção patrimonial contra a Fazenda Pública são legitimas, conforme já decidiu o STF em sede de antecipação de tutela. Todavia, observa Eurico Ferraresi, "não se pode esquecer o fato de que a multa diária recairá, diretamente, no patrimônio público, bem de todos, e que, por isso, os efeitos de uma multa aplicada ao setor particular e ao setor público podem ser completamente diversos. A imposição de multa diária só tem efeito quando recai no patrimônio particular do administrador público, pois, do contrário, onerar-se-ia ainda mais o erário". E continua anotando que, embora o montante da multa imposta possa ser cobrado posteriormente do responsável, seria necessária uma nova demanda judicial para a 
recuperação.[...] Assim, por diversas razões conclui-se que a imposição de multa diária não constitui a melhor medida para compelir o agente público a uma obrigação de fazer. (GRINOVER, 2013, p. 140-141)

Percebe-se que as sanções mais adequadas, ao descumprimento da ordem ou decisão judicial pelo Poder Público, são a responsabilização por ato de improbidade administrativa, a intervenção federal ou estadual no Estado ou Município; o crime de desobediência ${ }^{3}$; e, em âmbito mais limitado, a imputação ao Prefeito Municipal de crime de responsabilidade ${ }^{4}$. (GRINOVER, 2013)

Desde o reconhecimento dos direitos fundamentais sociais, foi expressamente previsto que ao Estado caberia a obrigação de garantir aos seus cidadãos um mínimo de condições essenciais exigidas para a sua existência com dignidade. Ao mesmo tempo, como não poderia ser diferente, em razão destes direitos, exigirem uma prestação estatal, surgiu também a discussão acerca dos limites das obrigações que devem ser cumpridas e de que forma o Estado deve implementá-las.

Tanto o Supremo Tribunal Federal, como o Superior Tribunal de Justiça, já acenaram com decisões, ora oscilando numa, ora oscilando noutra corrente. Inclusive o Conselho Nacional de Justiça tem tomado inciativas, em uma série de temas atinentes a políticas publicas, no âmbito do Poder Judiciário nacional. A tendência, contudo, é que, caso a caso, soluções sejam obtidas sem romper bruscamente com paradigmas consagrados e, ao mesmo tempo, sem deixar de zelar pelos direitos mais nobres, resguardados pela Constituição, como o caso da dignidade da pessoa humana. (GARCIA, 2008).

2 Ato de improbidade administrativa- atenta contra os princípios da Administração pública qualquer ação ou omissão que viole os deveres de honestidade, imparcialidade, legalidade e lealdade às instituições.

${ }^{3}$ Crime de desobediência - Consiste em desobedecer ordem legal de funcionário público no exercício da função.

${ }^{4}$ Crime de responsabilidade - espécie de violações do dever legal que podem ser cometidas apenas por agentes políticos. Essas infrações fazem parte do sistema de responsabilização dos agentes públicos no direito brasileiro. 


\section{REFERÊNCIAS}

APPIO, Eduardo. Controle Judicial das políticas Públicas no Brasil. 1 ed (2005) , 5 reimpressão. Curitiba: Juruá, 2012.

BRASIL. Constituição (1988). Constituição da República Federativa do Brasil. Brasília, DF, 1988.

BUCCI, Maria Paula Dallari. Fundamentos para uma Teoria Jurídica das Políticas Publicas.

São Paulo: Saraiva, 2013.

CANELA JUNIOR, Osvaldo. Controle Judicial de políticas públicas. São Paulo: Saraiva, 2011.

COELHO, Ailta. B.R. Política de proteção à infância e adolescência e descentralização. In: Revista Serviço Social e Sociedade, n. 60, ano XX, Julho de 1999. São Paulo: Cortez, 1999. P 92-105.

GARCIA, Rafael.B. O Poder Judiciário e as Políticas Públicas no Brasil: análise doutrinária e evolução casuística. Interesse Público, Belo Horizonte: Ano 10. N. 51 set/out/2008.

GIOVANNI, G. Di. As estruturas elementares das políticas públicas. Caderno de Pesquisa n.82, Campinas: NEPP/Unicamp, 2009.

GONÇALVES, Leonardo Augusto. Direitos Sociais: cidadania, política e justiça. Rio de Janeiro: Sinergia, 2013.

GRINOVER, Ada Pellegrini. O controle Jurisdicional de Políticas Públicas. Coord. Ada Pellegrini Grinover, Kazuo Watanabe. 2 ed., Rio de Janeiro: Forense, 2013.

GRINOVER, Ada Pellegrini. O controle Jurisdicional de Políticas Públicas. Coord. Ada Pellegrini Grinover, Kazuo Watanabe. 2 ed., Rio de Janeiro: Forense, 2013. P. 125 - 150

JACOB, Cesar Augusto Alckimin. A reserva do possível: obrigação de previsão orçamentária e de aplicação da verba. In: GRINOVER, Ada Pellegrini. O controle Jurisdicional de Políticas Públicas. Coord. Ada Pellegrini Grinover, Kazuo Watanabe. 2 ed., Rio de Janeiro: Forense, 2013. p. 235- 283. 
JORGE NETO, Nagibe de Melo. O controle jurisdicional das políticas públicas: concretizando a democracia e os direitos sociais fundamentais. Salvador: Jus Podivm, 2008.

NOGUEIRA, Marco Aurélio. O desafio de construir e consolidar direitos no mundo globalizado. Revista Serviço Social e Sociedade n. 82. São Paulo: Cortez, 2005. p.5-21.

SADEK, Maria Teresa. Judiciário e arena pública: um olhar a partir da ciência política. In: GRINOVER, Ada Pellegrini. O controle Jurisdicional de Políticas Públicas. Coord. Ada Pellegrini Grinover, Kazuo Watanabe. 2 ed., Rio de Janeiro: Forense, 2013. P. 1- 32

SOUZA, Rodriane de Oliveira. Participação e controle Social. In: SALES, Mione Apolinário (org.). Política Social, Família e Juventude: uma questão de direitos. 6 edição. São Paulo: Cortez, 2010. p. 167- 187

WATANABE, Kazuo. Controle jurisdicional das políticas públicas - "Mínimo existencial" e demais direitos fundamentais imediatamente judicializáveis. In: GRINOVER, Ada Pellegrini. O controle Jurisdicional de Políticas Públicas. Coord. Ada Pellegrini Grinover, Kazuo Watanabe. 2 ed., Rio de Janeiro: Forense, 2013. p. 213- 224.

ZUFELATO, Camilo. Controle judicial de políticas públicas mediante ações coletivas e individuais. In: GRINOVER, Ada Pellegrini. O controle Jurisdicional de Políticas Públicas. Coord. Ada Pellegrini Grinover, Kazuo Watanabe. 2 ed., Rio de Janeiro: Forense, 2013. p. 309- 331. 